4

5 Kejing Li, ${ }^{a 1,1}$ Monica Vasiliu, ${ }^{b}$ Casey R. McAlpin, ${ }^{a 2}$ Yuan Yang, ${ }^{a 2}$ David A. Dixon, ${ }^{b}$ Kent J.

\section{Further Insights into the Structure and Chemistry of the Gilsonite Asphaltene from a} Combined Theoretical and Experimental Approach.
Voorhees, ${ }^{a 2}$ Michael Batzle, ${ }^{a 3}$ Matthew W. Liberatore, ${ }^{a 1}$ and Andrew M. Herring. ${ }^{a 1, *}$

(1)

${ }^{a 1}$ Department of Chemical and Biological Engineering, ${ }^{a 2}$ Department of Chemistry and Geochemistry, and ${ }^{a 3}$ Department of Geophysics, Colorado School of Mines Golden, CO 80401 USA

${ }^{b}$ Department of Chemistry, The University of Alabama

Tuscaloosa, AL 35487 USA

13

4

Submitted to

Fuel

December 2014

\footnotetext{
*Corresponding author. Telephone: (303) 384-2082, e-mail address: aherring@ mines.edu.

${ }^{1}$ Current address: School of Chemical Engineering, East China University of Science and Technology, Shanghai, 200237 China.
} 
18 Gilsonite is a natural fossil resource, similar to a petroleum asphalt high in asphaltenes. 19 Asphaltenes are a class of organic compounds operationally defined based on their solubility in

20

21

22

23

24

25

26

27 organic solvents, and as a result there is wide range of potential compositions and structures that can fit into this class. Specific compounds are challenging to propose due to its complexity. A sample of the asphaltene derived from the Gilsonite deposit was characterized by Fourier transform infrared spectroscopy, Raman spectroscopy, and high-resolution transmission electron microscopy. The high intensity of the $1600 \mathrm{~cm}^{-1}$ infrared peak, which corresponds to a $\mathrm{C}=\mathrm{C}$ stretching vibrational mode of the aromatic carbons also found prevalent in other asphaltenes, is likely a characteristic asphaltene feature. The high intensity can be explained by the stack structure and/or by polycyclic aromatic infrared transitions with a high dipole moment derivative. The nanosize stack structure was validated by the electron microscope and diffraction patterns, giving inter-sheet distances of 2.54 and $3.77 \AA$, respectively. Complementary calculations using density functional theory suggest a specific island-type polycyclic aromatic molecular model, with the calculated vibrational modes consistent with all of the characteristic peaks in the infrared spectrum. The method combining theoretical and experimental can be extended for more specific asphaltene molecular structure identifications.

\section{Highlights}

- Combined computational and experimental approaches to characterize asphaltenes.

- $1600 \mathrm{~cm}^{-1}$ IR peak with large intensity identified as a characteristic asphaltene feature.

- Nanosize stack moieties found by TEM and SAED.

- An 'island' molecular model validated by experimental and calculated spectra. 


\section{Keywords}

40 Gilsonite, asphaltene, vibrational spectroscopy, transmission electron microscopy, density

41 functional theory

\section{$42 \quad$ Introduction}

The world uses more than $90 \mathrm{Mt}$ asphalts every year, among which about $60-70 \%$ is used

44 for road paving, 10-20\% for waterproofing and anticorrosive materials, and 10-20\% for other

45 industrial applications [1]. Gilsonite is a well-known natural deposit of bituminous asphalt

46 primarily located in the Black Dragon and Bonanza area in the eastern Utah basins and has been

47 of wide interest and use [2]. It can be in liquid or solid form, possibly originating from protein

48 transformations and biodegradations [3]. Solid gilsonite is known for its high content of

49 asphaltene [4]. Asphaltenes, usually derived either from coal or from petroleum vacuum

50 distillation residues, are wide-spread, and a class of compounds that are defined by their

51 solubility, i.e. insoluble in n-heptane and soluble in toluene [5]. Gilsonite ${ }^{\mathrm{TM}}$ is produced with a

52 fair degree of quality control so as it has consistent properties. It is a useful substance in which to

53 study asphaltenes, to compare with the petroleum asphaltenes, and further understand their

54 chemistry and structure.

55 There have been numerous studies to understand asphaltene components and their 56 structures utilizing a range of analytical methods based on references cited therein [6,7]. Progress

57 is being made, with a broad range of studies being carried out to develop asphaltene molecular

58 models [8-13]. Raman and infrared (IR) spectroscopy are complementary techniques for 59 observing molecular vibrations based on polarizability and dipole moment changes, respectively.

60 Raman spectroscopy is useful in identifying structures with both long-range order and short- 
61 range order and has been applied to asphaltene characterization [14]. Alkyl chain content derived

62 from IR spectra has been quantitatively related to insolubility [15].Transmission electron

63 microscopy (TEM) has been used to determine asphaltene microstructure and micelle size [16],

64 providing a size range limit for asphaltene molecules. Computational methods were applied to

65 probe possible structures and to compare with experimental nuclear magnetic resonance spectra

66 and Raman spectra, and the highest occupied molecular orbital-lowest unoccupied molecular

67 orbital gap was related to observed optical spectra [17-20]. The actual asphaltene composition

68 covers a wide span of molecules from low to high molecular weights, and various core structures.

69 Different conditions such as the origin of the asphaltene, separation solvents, analytical methods,

70 etc. result in assignment variations. A structure that is likely to be one of the many possibilities

71 for asphaltene candidates is easy to propose; yet its verification requires independent

72 experimental evidence to prove its existence or exclude the possibility. In this work, we use both

73 experimental and computational methods to provide a more accurate basis for asphaltene

74 chemical identification.

75 Experimental Section

76 Materials. The sample used in this study was an asphaltene fraction from the Gilsonite

77 deposits in the Bonanza area in eastern Utah supplied from a commercial source. The sample 78 preparation using column distillation, n-heptane precipitation, toluene filtration, and drying, were 79 all done by the source who provided the sample. No further treatment was performed.

Spectroscopy. Fourier transform infrared spectra (FTIR) were acquired on a Thermo

81 Nicolet 870 spectrometer in transmission mode. The solid sample was ground with anhydrous

$82 \mathrm{KBr}$ powder and hydraulically pressed to form a grey opaque pellet. Before taking the sample 83 spectrum, an IR spectrum of a blank $\mathrm{KBr}$ pellet window was taken as the background. The 
84 spectrum was collected with a resolution of $4 \mathrm{~cm}^{-1}$ from $4000 \mathrm{~cm}^{-1}$ to $400 \mathrm{~cm}^{-1}$ for 100 scans 85 using a deuterated triglycine sulphate detector.

87 charge-coupled device as the detector. The laser beam wavelength used was $532 \mathrm{~nm}$; the power was approximately $15 \mathrm{~mW}$ concentrated on the sample with a $100 \mathrm{x}$ objective lens. Prior to 89 sample measurement, a Si wafer was used for the alignment and instrument calibration test. A $600 \mathrm{~g} / \mathrm{mm}$ dispersion grating was used for the measurements. The ground sample particles were 91 then placed on a glass slide and packed to about $1 \mathrm{~mm}$ in thickness. Each spectrum was taken as 92 an average of 20 scans with an exposure time of $2 \mathrm{~s}$ at each scan.

Microscopy. High resolution transmission electron microscopy (HRTEM) and selected 94 area electron diffraction (SAED) were done on a FEI CM200 to search for the presence of any crystalline structures in the asphaltene. The solid samples were ground to micro-particle sizes and suspended in methanol, followed by coating on a copper grid (Holey Carbon Film on 300 97 mesh copper, from Electron Microscopy Sciences). The measurements were at a $200 \mathrm{kV}$ emission voltage (electron wavelength $\lambda$ of $2.74 \mathrm{pm}$ ) and a $10^{7}$ magnification to the imaging 99 plates used a $2 \mathrm{k} \times 2 \mathrm{k}$ CCD camera with an image resolution of about $2.4 \AA$. The camera length was calibrated using an evaporated $\mathrm{Al}$ film at the same lens current and emission voltage. The electron diffraction pattern was then processed using the ProcessDiffraction program [21].

Computational Methods. The geometries were optimized using density functional theory 103 (DFT) with the hybrid B3LYP exchange-correlation functional $[22,23]$ and the $6-31+G(d, p)$ 104 basis set [24]. The geometries were also optimized using the semi-empirical PM6 molecular 105 orbital method and the vibrational frequencies were calculated at both levels [25]. These 
electronic structure calculations were done with the Gaussian09 program system [26]. Spectral broadening was added by giving each line a Lorenztian line shape with a $5 \mathrm{~cm}^{-1}$ line width.

\section{Results and Discussion}

FTIR and Raman Spectra. The solid Gilsonite asphaltene sample's main Raman shifts and IR vibrational peaks are labeled in Figure 1(a). These spectra are similar to asphaltene spectra observed and assigned by other researchers [14,18,27]. This indicates that Gilsonite asphaltene should have similar basic structures as that of asphaltenes from other sources, as evidenced by the similarities in their Raman and infrared spectra. In our earlier work on heavy oil analysis, it was noticed that certain heavy oil FTIR peaks such as the ones at $1390 \mathrm{~cm}^{-1}$ and $1600 \mathrm{~cm}^{-1}$ have an unusually high intensity and the extra intensity may correspond to asphaltene contribution [28]. A comparison of transmission FTIR spectra for the asphaltene and heavy oil, which is a mixture of saturates, aromatics, resins, and asphaltenes, corroborates this statement as shown in Figure 1(b). When the spectra are normalized with respect to the $2920 \mathrm{~cm}^{-1} \mathrm{C}-\mathrm{H}$ stretching peak, in the asphaltene IR spectrum, the $1600 \mathrm{~cm}^{-1}$ peak is significantly more intense than that of the heavy oil with an asphaltene fraction. This indicates that the prominent $1600 \mathrm{~cm}^{-1}$ peak observed in many heavy oil and asphaltene IR experiments should be partly assigned to an asphaltene characteristic peak, whose intensity is stronger than that of many aromatic molecules. However, the structural reason leading to the increased intensity has not yet been uncovered. In the petroleum literature, these two peaks are usually assigned as $\mathrm{C}=\mathrm{C}$ stretching and $\mathrm{C}$ $\mathrm{H}$ bending modes, respectively [29]. Although the band at $\sim 1600 \mathrm{~cm}^{-1}$ is not unique to asphaltenes as many aromatics may have peaks around this value, their intensities are not always as strong. Very few aromatic substances if any in the IR database have a similar spectrum as that of asphaltene [30]. Most of them have peaks around these wavenumbers, but at the same time, 
129 have very intense peaks at other wavenumbers that do not match the asphaltene spectrum. It is 130 still challenging to find a model that has all the peak locations and peak intensities that match the 131 asphaltene spectrum; however, the $1600 \mathrm{~cm}^{-1}$ intensity can be used as a guide to screen models. Besides the $1600 \mathrm{~cm}^{-1}$ peak, a broad shoulder to the lower wavenumber region at 1375 $133 \mathrm{~cm}^{-1}$ is prominent in Figure 1. In many reports for carbonaceous materials, there are similar 134 characteristic peaks close to the two observed peaks, e.g. 1587 and $1362 \mathrm{~cm}^{-1}$ in the FTIR 135 spectrum for ground graphite [31], and the $\mathrm{G}\left(1580 \mathrm{~cm}^{-1}\right)$ and $\mathrm{D}\left(1350 \mathrm{~cm}^{-1}\right)$ bands in the Raman 136 spectra for charcoals, carbon fibers, and soot [32-36]. The $G$ band can shift to higher 137 wavenumbers when the graphite crystal size becomes smaller, and the D band results from the 138 small crystallinity of graphite, symmetry-breaking at the edges, or nanometer size disorders $139[33,35]$. Bouhadda et al. also observed the G and D bands in the Raman spectra of an asphaltene, 140 but did not attribute them to asphaltene characteristic bands [14]. In their report, the D band was 141 deconvoluted with different assignments to estimate asphaltene molecular dimensions, and one 142 of them was related to non-crystal carbon black, which is a graphite-like, quasi-crystalline 143 species [37]. Besides the $1600 \mathrm{~cm}^{-1}$ and $1350 \mathrm{~cm}^{-1}$ peaks, there is a small peak around $2730 \mathrm{~cm}^{-1}$ 144 in the IR spectrum, which is apparent in both the heavy oil and asphaltene IR spectra. A low 145 broad "hum" near this region exists in the Raman spectrum (Figure 1(a)). As a comparison, a 146 second-order of zone-boundary phonons peak named 2D has been reported for glassy carbon 147 [38]. From these similarities, one explanation for the prominent $1600 \mathrm{~cm}^{-1}$ peak observed in 148 many heavy oil and asphaltene IR experiments is that the intensity is contributed by structures 149 similar to the well-known Yen's 'asphaltene micelle', or qualitatively described as a 'graphite150 type stack' [39], which may arise from the intermolecular attractions between asphaltene 151 molecules through "aromatic planes" [40]. 
The full width at half maximum (FWHM) of the peaks in the Raman spectrum (Figure 153 1(a)) are about $170 \mathrm{~cm}^{-1}$ for the $1600 \mathrm{~cm}^{-1}$ peak and $270 \mathrm{~cm}^{-1}$ for the $1350 \mathrm{~cm}^{-1}$ peak, 154 respectively. The FWHMs are greater than those for single crystal graphite [33]. The difference 155 may arise from the low crystalline quality of stack domains in asphaltene, with larger amounts of 156 plastic deformation or disorder, besides instrumental resolution differences. In addition, it could 157 be due to a broader range of compounds with varying amounts of different types of $\mathrm{C}=\mathrm{C}$ bonding 158 which would broaden the peak.

HRTEM. Ultrafine random oriented nanocrystalline structures were found in some of the 160 asphaltene particles on the TEM grid as shown in Figure 2. The contrast interface of the darker region and the brighter region corresponds to possible phase boundaries between the 162 polycrystalline structures and the amorphous materials or some structures at a different zone axis. 163 In addition, crossing fringes seem to exist in one grain. This is a validation of the previous FTIR 164 hypothesis that quasi-crystalline stacks might exist in this asphaltene. The upper left corner and 165 in the middle of Figure 2(a) of the HRTEM image, lattice fringes of $\sim 2.54,3.77$, and $10.90 \AA$ 166 spacings are noticeable, of which the former two are consistent with reported asphaltene layer 167 dimensions of 2.1-5.3 $\AA$ measured by XRD [41], while the one at $10.90 \AA$ is not very clear but 168 might be due to the nanocrystalline boundaries of stacked layers. Overall, the results suggest a 169 stack layer number of between 2 and 5. The spread range of these lattices is a few tens of 170 nanometers as seen in the dark region in Figure 2(a), which reflects the agglomeration size of 171 these nanocrystallites. The spacing of $3.77 \AA$ is close to but a little greater than the reported 172 distance of $3.55-3.70 \AA$ for graphite $[42,43]$. Thus the stack is similar to a graphite sheet, but 173 different in that it contains steric distortions due to peripheral alkyl groups on the stacked 174 polycyclic aromatics, or some other type of small clusters of fused rings, such as porphyrins, 
175 which are known to self-assemble and form stacked structures [2,40]. Separation of these stack 176 domains is difficult and poses a challenge in the analysis of the FTIR assignments in terms of the $1771600 \mathrm{~cm}^{-1}$ peak intensity. The straight rather than round lattice spacings indicate that they are 178 more likely to be sheet-stacked nano-clusters and not other allotropic structures (i.e. diamond, or 179 fullerene-like species). Among the micro-particles tested, some are amorphous and not all 180 particles show diffraction rings, as given in Supplementary Data A, Figure S1. The TEM image 181 reflects the size of asphaltene micelles in agreement of the size range as found by others, and the 182 crystalline region corroborates the view that the asphaltene may tend to form stack domains [27]. An SAED ring pattern for the HRTEM and its analysis is shown in Figure 2(b) and (c). Peaks in Figure 2(b) correspond to the diffusion rings in Figure 2(c). Three peaks or rings are 185 observable. The weak intensities are due to the small amount of crystalline material. The peak at $1862.34 \AA$ is of lower indices than the peak at $1.35 \AA$, and may correspond to the $2.54 \AA$ lattice 187 fringes domains in Figure 2(a). The value variation is due to the spatial resolution limit when 188 finding and scaling the fringes in the HRTEM image. The spotty Debye rings instead of points or 189 continuous lines in Figure 2(c) can also be due to different asphaltene crystalline stacking 190 patterns or amorphous species of short-range order. More studies are needed to conclude whether 191 these values can account for the aromatic sheet distances in an asphaltene cluster crystalline 192 moiety. Overlapping of other lower indices with the direct beam is possible and makes it difficult 193 to determine the lattice constant.

Molecular Modeling. The infrared spectrum from an electronic structure calculation can 195 be helpful in in interpreting the observed spectra, as there are unlikely to be actual reference 196 materials for the assignments. As discussed earlier, the high intensity of $1600 \mathrm{~cm}^{-1}$ IR peak is 197 likely an asphaltene characteristic feature. The stack structure may have caused this high 
198 intensity, as corroborated by Raman experiments and TEM observations of carbonaceous 199 materials. However, this relatively prominent and high intensity $1600 \mathrm{~cm}^{-1}$ peak is not observed 200 in many aromatic IR spectra so it is difficult to find the correct molecular model. As the IR 201 intensity is proportional to a dipole moment derivative, this suggests the presence of a substituent 202 on the aromatic ring leading to an enhanced dipole derivative, which was suggested by other 203 researchers by the observations using $15 \mathrm{~N}$ nuclear magnetic resonance for the same source 204 material Gilsonite [2]. This feature in the IR spectra can be a potential indicator for use in 205 probing asphaltene markers, and as a benchmark for screening the electronic calculation of 206 specific asphaltene molecules used to model asphaltene. Following on studies supporting an 'island' type structure as a dominant asphaltene 208 structure [12,44], a heuristic model was constructed as shown in Figure 3 (structure as given in 209 Supplementary Data A, Table S1), which contains 4 fused rings in the molecule with $1 \mathrm{~N}$ 210 heteroatom. Its $\mathrm{H}: \mathrm{C}$ ratio is about 1.34 similar to the average Gilsonite asphaltene's ratio 211 (Supplementary Data A, Table S2). Its calculated IR spectrum is close to the experimental 212 observed Gilsonite IR spectrum, and has a molecular weight of $401 \mathrm{Da}$. The double bond 213 equivalence (DBE) of the model molecule is 11. The maximum dimension of the molecule is 214 about $15 \AA$, and the cross section thickness is about $3 \AA$, which is also within the lattice spacing 215 as observed in the HRTEM image in Figure 2.

217 have been calculated to help interpret the Gilsonite FTIR spectrum (Supplementary Data A, 218 Figure S2). The intensity of the asphaltene characteristic peak $1600 \mathrm{~cm}^{-1}$ is not directly 219 proportional to the number of rings. Among the investigated models, more core rings do not 220 necessarily lead to a more intense peak at $\sim 1600 \mathrm{~cm}^{-1}$ (Supplementary Data A, Figure S3). 
221 However, future investigations in screening the listed thousands of candidates are necessary to

222 unveil this correlation.

\section{4. Conclusions}

224 Gilsonite asphaltenes are similar with other petroleum source asphaltenes, having a polar 225 core and tend to interact and form aggregates or macromolecules not seen in simple liquids. A 226 short-range ordered structure was observed by TEM and SAED, forming stack domains. The 227 intense IR vibrational band at $1600 \mathrm{~cm}^{-1}$ is identified as a feature peak of asphaltenes and serves 228 as a benchmark for the calculation of vibrational spectra using electronic structure methods. 229 This intense IR peak may be explained by two reasons: the stack structure as observed by TEM 230 and/or the presence of polycyclic aromatics with a large dipole derivative as calculated by DFT. 231 Island-type structures are possible in Gilsonite asphaltene. One model compound with a 232 heteroatom and four rings provides a good calculated spectral match with the Gilsonite 233 asphaltene's experimental IR spectrum. Further work with in-depth analysis using computational 234 chemistry to validate the molecules observed by other experimental tools such as mass 235 spectrometry can be extended to provide more possible asphaltene compound candidates.

\section{Acknowledgements}

237 This work was supported by the U.S. Department of Energy, under contract DE-NT-0005663 to 238 the Colorado School of Mines and by the DOE Office of Basic Energy Sciences, Geosciences 239 program (DE-SC0009362). The authors appreciate the HRTEM measurements by Dr. Gary Zito 240 and ICP-OES tests in Prof. James Ranville's lab. K. Li thanks the Fundamental Research Funds

241 for the Central Universities (22A20154009). D. A. Dixon thanks the Robert Ramsay Chair Fund 242 of The University of Alabama for partial support. 
243 In Memoriam of Dr. Michael Batzle, who was a geophysicist and a great scholar to have 244 worked with.

245 Appendix A. Supplementary Material

246 Supplementary data associated with this article can be found, in the online version, at

247 www.fuel.org.

$248 \quad$ References

[1] Ou F. Petroleum Products Application and Technology Handbook. Bejing, China: Sinopec Press; 1998; p. 913.

[2] Helms JR, Kong X, Salmon E, Hatcher P, Schmidt-Rohr K, Mao J. Structural characterization of gilsonite bitumen by advanced nuclear magnetic resonance spectroscopy and ultrahigh resolution mass spectrometry revealing pyrrolic and aromatic rings substituted with aliphatic chains. Org Geochem 2012;44:21-36.

[3] Hunt JM. Paper 24, Oil and gas possibilities of Utah, re-evaluated. In: Utah Geol And Mineralog Surv Bull 54; 1963; 249-273.

[4] Ziegler Chemical \& Mineral Corporation, Chemical properties of Gilsonite, Available from: http://www.zieglerchemical.com/chemprop.htm.

[ 5 ] Goual L. Petroleum asphaltenes, crude oil emulsions-composition stability and characterization; Prof. Manar El-Sayed Abdul-Raouf (Ed.), InTech; 2012. Available from: http://www.intechopen.com/books/crude-oil-emulsions-composition-stability-andcharacterization/petroleum- asphaltenes.

[6] Calemma V, Iwanski P, Nali M, Scotti R, Montanari L. Structural characterization of asphaltenes of different origins. Energy Fuels 1995;9:225-230. 
[7] Herod AA, Bartle KD, Morgan TJ, Kandiyoti R. Analytical methods for characterizing highmass complex polydisperse hydrocarbon mixtures: an overview. Chem Rev 2012;112:3892-3923. [8] Carbognani L. Molecular structure of asphaltene proposed for 510C residue of Venezuelan crude, In: INTEVEP SA Tech Report; 1992.

[9] Li DD, Greenfield ML. Chemical compositions of improved model asphalt systems for molecular simulations. Fuel 2014;115:347-356.

[10] Ruiz-Morales Y. HOMO-LUMO Gap as an Index of Molecular Size and Structure for Polycyclic Aromatic Hydrocarbons (PAHs) and Asphaltenes: A Theoretical Study. I. J Phys Chem A 2002:106:11283-11308.

[11] Siskin M, Kelemen SR, Eppgi CP, Brown LD, Afewoki M. Asphaltene molecular structure and chemical influences on the morphology of coke produced delayed coking. Energy Fuels 2006;20:1227-1234.

[12] Mullins OC. The modified Yen model. Energy Fuels 2010;24:2179-2207.

[13] Ruiz-Morales Y, Mullins OC. Polycyclic aromatic hydrocarbons of asphaltenes analyzed by molecular orbital calculations with optical spectroscopy. Energy Fuels 2007;21:256-265.

[14] Bouhadda Y, Bormann D, Sheu E, Bendedouch D, Krallafa A, Daaou M. Characterization of Algerian Hassi-Messaoud asphaltene structure using Raman spectrometry and X-ray diffraction. Fuel 2007;86:1855-1864.

[15] Carbognani L, Espidel J, Izquierdo A. Characterization of asphaltenic deposits from oil production and transportation operations, in: Yen TF, Chilingarian GV (Eds.), Asphalts and asphaltenes, 2, Developments in petroleum science series, vol. 40B, Elsevier, New York (2000), pp. 335-362. 
[16] Pérez-Hernández R, Mendoza-Anaya D, Mondragón-Galicia G, Espinosa ME, RodríguezLugo V, Lozada M, Arenas-Alatorre J. Microstructural study of asphaltene precipitated with methylene chloride and n-hexane. Fuel 2003;82:977-982.

[ 17 ] Sheremata JM, Gray MR, Dettman HD, McCaffrey WC. Quantitative molecular representation and sequential optimization of Athabasca asphaltenes. Energy Fuels 2004;18:1377-1384.

[18] Andrews AB, Wang D, Marzec KM, Mullins OC, Crozier KB. Surface enhanced Raman spectroscopy of polycyclic aromatic hydrocarbons and molecular asphaltenes. Chem Phys Lett 2015;620:139-143.

[19] Ruiz-Morales Y, Wu X, Mullins OC. Electronic absorption edge of crude oils and asphaltenes analyzed by molecular orbital calculations with optical spectroscopy, Energy Fuels 2007;21:944-952.

[20] Leon O, Rogel E, Espidel J, Torres G. HOMO-LUMO gap as an index of molecular size and structure for polycyclic aromatic hydrocarbons (PAHs) and asphaltenes: a theoretical study. Energy Fuels 2000;14:6-10.

[21] Lábár JL. Consistent indexing of a (set of) single crystal SAED pattern(s) with the ProcessDiffraction program. Ultramicroscopy 2005;103:237-249.

[22] Becke AD. A new mixing of Hartree-Fock and local density-functional theories. J Chem Phys 1993;98:1372-1377.

[23] Lee C, Yang W, Parr RG. Development of the Colle-Salvetti correlation-energy formula into a functional of the electron density. Phys Rev B 1988;37:785-789. 
[24] Hariharan PC, Pople JA. The influence of polarization functions on molecular orbital hydrogenation energies. Theoret Chimica Acta 1973;28:213-222.

[25] Stewart JJP. Optimization of parameters for semiempirical methods V: modification of NDDO approximations and application to 70 elements. J Mol Model 2007;13:1173-1213.

[26] Gaussian 09, Revision A.1, Frisch MJ, Trucks GW, Schlegel HB, Scuseria GE, Robb MA, Cheeseman JR, Scalmani G, Barone V, Mennucci B, Petersson GA, Nakatsuji H, Caricato M, Li X, Hratchian HP, Izmaylov AF, Bloino J, Zheng G, Sonnenberg JL, Hada M, Ehara M, Toyota K, Fukuda R, Hasegawa J, Ishida M, Nakajima T, Honda Y, Kitao O, Nakai H, Vreven T, Montgomery Jr JA, Peralta JE, Ogliaro F, Bearpark M, Heyd JJ, Brothers E, Kudin KN, Staroverov VN, Kobayashi R, Normand J, Raghavachari K, Rendell A, Burant JC, Iyengar SS, Tomasi J, Cossi M, Rega N, Millam NJ, Klene M, Knox JE, Cross JB, Bakken V, Adamo C, Jaramillo J, Gomperts R, Stratmann RE, Yazyev O, Austin AJ, Cammi R, Pomelli C, Ochterski JW, Martin RL, Morokuma K, Zakrzewski VG, Voth GA, Salvador P, Dannenberg JJ, Dapprich S, Daniels AD, Farkas Ö, Foresman JB, Ortiz JV, Cioslowski J, Fox, DJ. Wallingford CT: Gaussian, Inc; 2009.

[27] Pérez-Hernández R, Mendoza-Anaya D, Mondragón-Galicia G, Espinosa ME, RodríguezLugo V, Lozada M, Arenas-Alatorre J. Microstructural study of asphaltene precipitated with methylene chloride and n-hexane. Fuel 2003;82:977-982.

[28] Li K, McAlpin CR, Akeredolu BA, Bazyleva A, Voorhees KJ, Batzle M, Liberatore MW, Herring AM. A rheological and chemical investigation of Canadian heavy oils from the McMurray formation. Energy Fuels 2012;26:4445-4453. 
[29] Fossen M, Kallevik H, Knudsen KD, Sjöblom J. Asphaltenes precipitated by a two-step precipitation procedure. 2. physical and chemical characteristics. Energy Fuels 2011;25:35523567.

[30] Coblentz Society, Inc. NIST Chemistry WebBook; National Institute of Standards and Technology, Gaithersburg MD, 20899 (http://webbook.nist.gov).

[31] Friedel RA, Carlson GL. Infrared spectra of ground graphite. J Phys Chem. 1971;75:11491151.

[32] Hernandez Y, Nicolosi V, Lotya M, Lotya M, Blighe FM, Sun Z, De S, McGovern IT, Holland B, Byrne M, Gun'Ko YK, Boland JJ, Niraj P, Duesberg G, Krishnamurthy S, Goodhue R, Hutchison J, Scardaci V, Ferrari AC, Coleman JN. High-yield production of grapheme by liquid-phase exfoliation of graphite. Nature Nanotech 2008;3:563-568.

[33] Wang Y, Alsmeyer DC, McCreey RL. Raman Spectroscopy of Carbon Materials: Structural Basis of Observed Spectra. Chem Mater 1990;2:557-563.

[34] Tuinstra F, Koenig JL. Raman spectrum of graphite. J Chem Phys 1970;53:1126-1130.

[35] Fauteux C, Pegna J. Radial characterization of 3D-LVCD carbon fibers by Raman spectroscopy. Appl Phys A 2004;78:883-888.

[36] Herdman JD, Connelly BC, Smooke MD, Lon MB, Miller JH. A comparison of Raman signatures and laer-induced incandescence with direct numerical simulation of soot growth in non-premixed ethylene/air flames. Carbon 2011;49:5298-5311.

[37] Ungár T, Gubicza J, Ribárik G, Pantea C, Zerda TW. Microstructure of carbon blacks determined by X-ray diffraction profile analysis. Carbon 2002;40:929-937. 
[38] Nemanich RJ, Solin SA. First- and second-order Raman scattering from finite-size crystals of graphite. Phys Rev B 1979;20:392-401.

[39] Speight JG. The Chemistry and Technology of Petroleum, $5^{\text {th }}$ ed. Boca Raton, FL: CRC Press; 2014, pp. 352.

[40] Murgich J, Jesús M, Aray Y. Molecular recognition and molecular mechanics of micelles of some model asphaltenes and resins. Energy Fuels 1996, 10: 68-76.

[41] Yen TF, Erdman JG, Pollack SS. Investigation of the structure of petroleum asphaltenes by X-ray diffraction. Anal Chem 1961;33:1587-1594.

[42] Wang Y, Alsmeyer DC, McCreey RL. Raman Spectroscopy of Carbon Materials: Structural Basis of Observed Spectra. Chem Mater 1990;2:557-563.

[43] Rogel E. Studies on asphaltene aggregation via computational chemistry. Colloids and Surfaces A: Physicochem Eng Aspects 1995;104:85-93.

[44] Sabbah H, Morrow AL, Pomerantz AE, Zare RN. Evidence for island structures as the dominant architecture of asphaltenes. Energy Fuels 2011;25:1597-1604. 


\section{Figures Captions}

250 Figure 1. (a) Raman (top) and transmission FTIR (bottom) spectra of the solid Gilsonite

251 asphaltene; (b) FTIR spectra of the solid Gilsonite asphaltene (red line, shaded, same spectrum as

252 in (a)) and heavy oil (Canadian, $434 \mathrm{~m}$, black line), both normalized to the peak at $2920 \mathrm{~cm}^{-1}$.

253 Figure 2. (a) HRTEM image; (b) the intensity distribution of an electron diffraction pattern, K is

254 the inverse of lattice spacing; and (c) an electron diffraction pattern of one Gilsonite asphaltene 255 particle, camera length $150 \mathrm{~mm}$.

256 Figure 3. (a) Transmission FTIR spectra of Gilsonite asphaltene (same as in Figure 1), and (b)

257 calculated IR spectrum for model $\mathrm{C}_{29} \mathrm{H}_{39} \mathrm{~N}$ with a scaling factor of 0.9404 . 


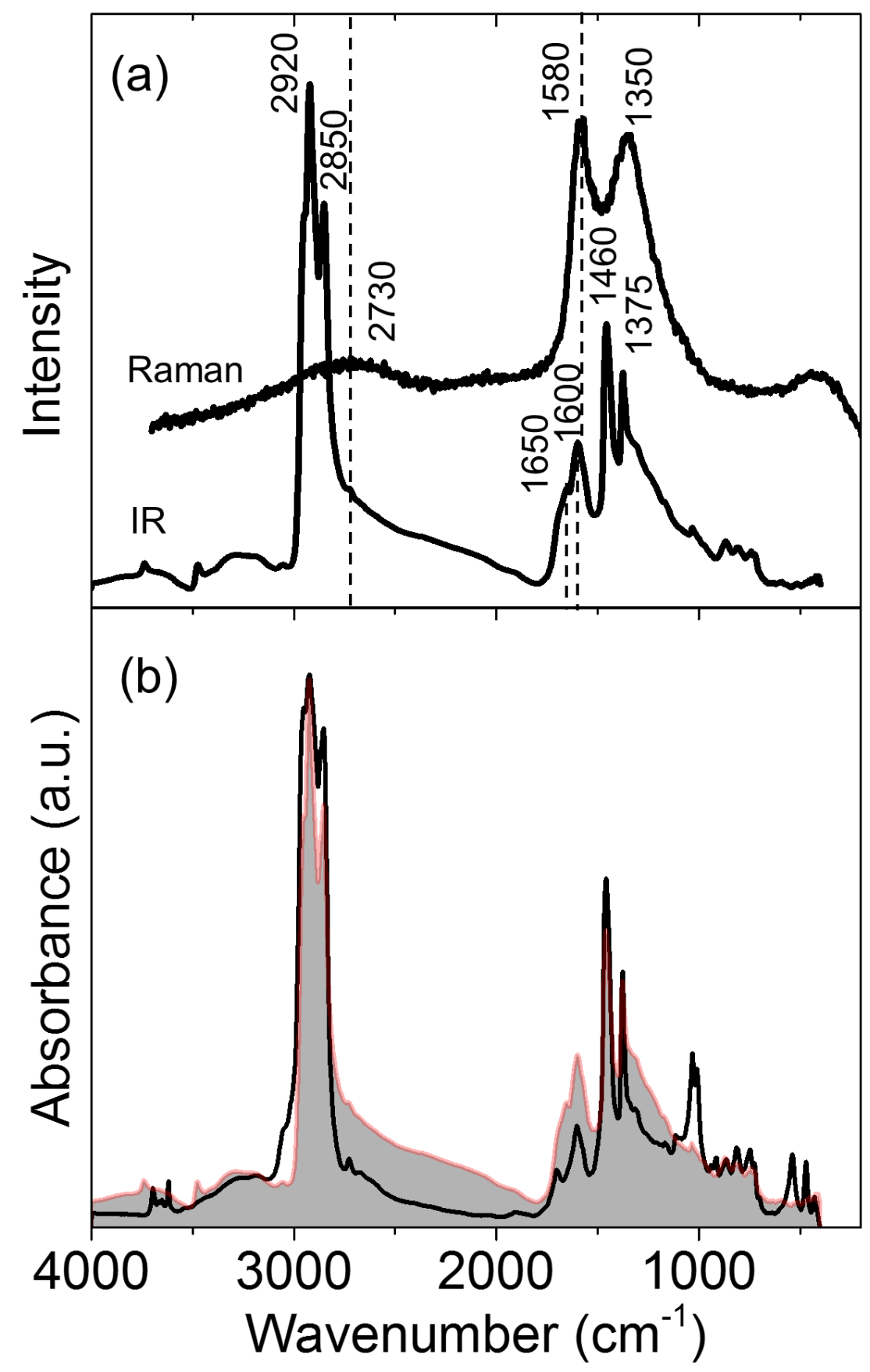

Figure 1. 

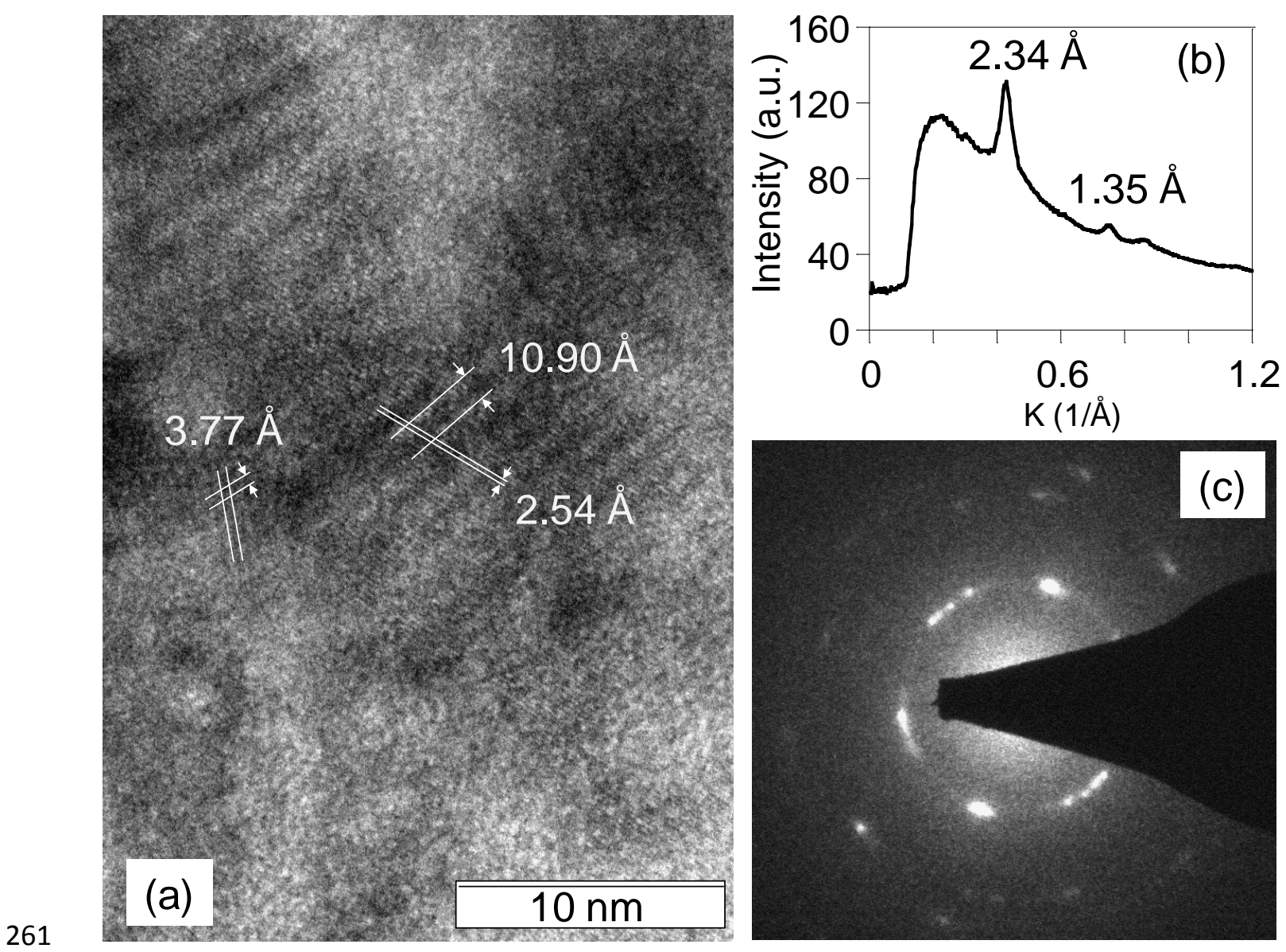

262 Figure 2. 


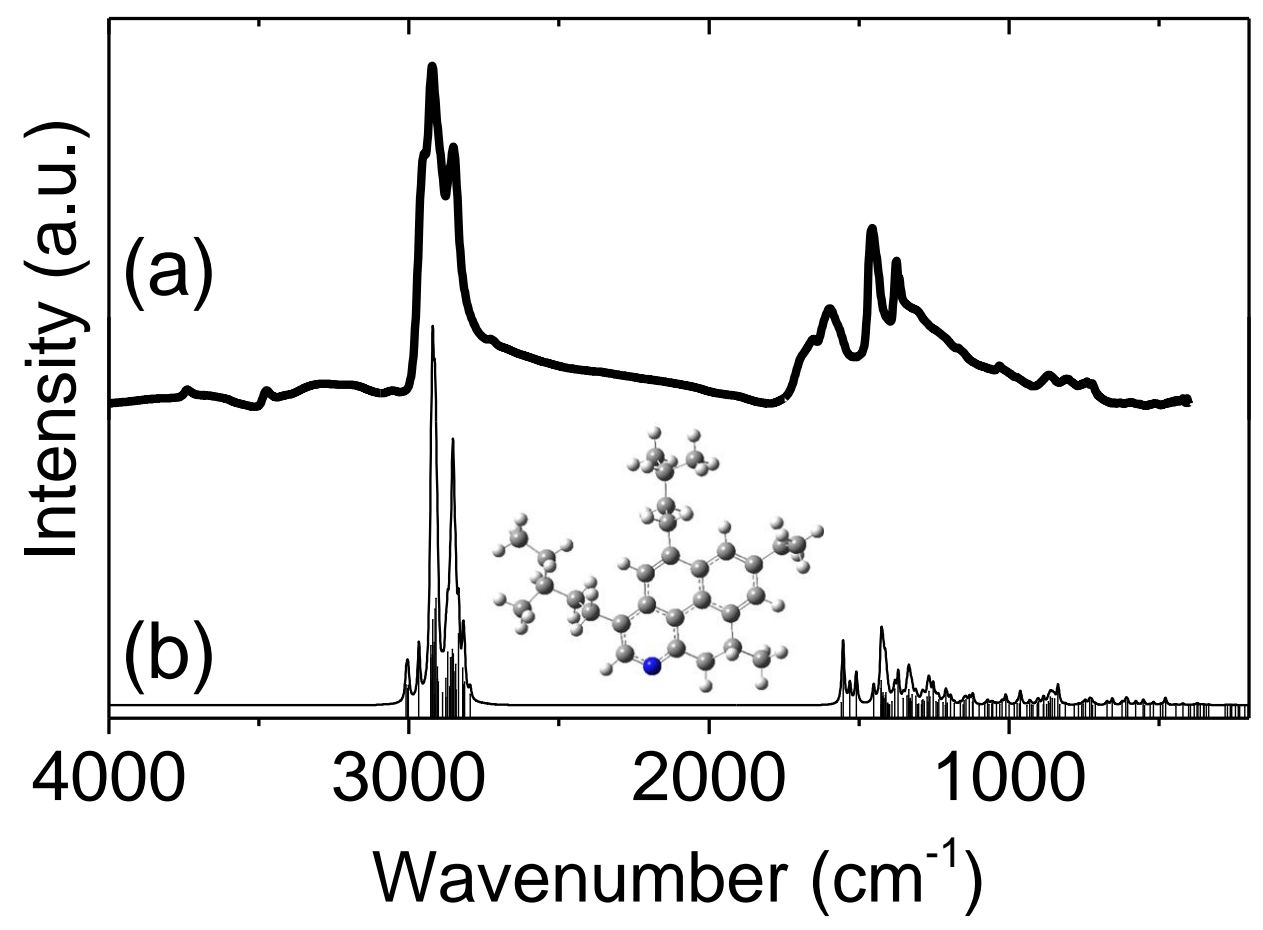

264 Figure 3. 